Original Article

\title{
FRUIT PEEL EXTRACTS WITH POTENTIAL FOR DISSOLVING SIMULATED RENAL STONES IN IN VITRO CONDITIONS
}

\author{
KARUNA SREE VARICOLA ${ }^{a}$, AMREEN SIDDIQUA A. ${ }^{b}$, KEERTHI DINTYALAc, GANDHI VENTRAPATId
}

aAssociate Professor, Head of the Department, Department of Pharmacognosy, KVSR Siddhartha College of Pharmaceutical Sciences, Vijayawada, b,c,dKVSR Siddhartha College of Pharmaceutical Sciences, Pinnamaneni Polyclinic Road, Siddhartha Nagar, Vijayawada, Andhra Pradesh, India

Email: kspamula@gmail.com

Received: 09 Jun 2018 Revised and Accepted: 05 Oct 2018

ABSTRACT
Objective: To evaluate the antiurolithiatic activity of selected fruit peels on simulated renal stones in in vitro conditions.

Methods: Simulated renal stones were prepared by homogenous precipitation method. The criterion selected was to estimate the amount of calcium oxalate remaining in the semi-permeable membranes by Kramer and Tisdal method with slight modification. A suitable media was provided by TRIS buffer.

Results: The crude methanol extract of Musa sapientum exhibited highest dissolution of calcium oxalate ie.9.15 mg and the percent dissolved was found to be $91.5 \%$ in comparison to Malus pumila methanol extract which dissolved $8.96 \mathrm{mg}(89.6 \%)$ and Punica granatum methanol extract which dissolved $8.0 \mathrm{mg}$ (80.0\%). Its activity was comparable with that of standard drug Tamsulosin hydrochloride ( $400 \mathrm{mg}$ ) with a percentage dissolved of about $90.5 \%$.

Conclusion: Experimental evidence showed that methanol and aqueous fruit peel extracts of Musa sapientum, Malus pumila, and Punica granatum possess potential antiurolithiatic activity. Their effect is found to be significant and the extracts can be used in the treatment of lithiasis.

Keywords: Herbal medicine, Calcium oxalate, Homogenous precipitation, TRIS buffer, Antiurolithiathic activity

(C) 2018 The Authors. Published by Innovare Academic Sciences Pvt Ltd. This is an open access article under the CC BY license (http://creativecommons.org/licenses/by/4.0/) DOI: http://dx.doi.org/10.22159/ijpps.2018v10i11.27862

\section{INTRODUCTION}

Plants have been used for health and medical purposes for several thousands of years. Plants are valuable and eminent sources of new therapeutic agents that help to alleviate human ailments and promote health [1]. It is estimated that 35,000 to 70,000 plant species have, at one time or the other, been used in some cultures for medicinal purposes. Herbal remedies are often used to provide first-line and basic health services both to people living in remote areas where it is the only available health service and to people living in economically backward areas where it offers the only affordable remedy [2]. Fruit peels are discarded in the majority of common fruits even though they are found to be safe for consumption. Fruit peels are rich in antioxidants [3] and are the best source of rough dietary fibre [4]. Peels are low in calories, sugars, fats and are free from cholesterol. Fruit peels serve as a good source of vitamin-A, B-complex vitamins, minerals such as calcium, selenium, manganese, zinc, etc., [5].

$75 \%$ of the active constituents of Malus pumila (apple), Family: Rosaceae, are found in or directly beneath its skin. Oligosaccharides from apples are more effective at killing cancer cells than chemotherapy [6]. Polyphenols and flavonoids in apple fruit and skin are anti-inflammatory. Apple peels are versatile biomass for water purification by removing the toxic anions from water [7]. An apple peel contains a waxy compound called ursolic acid, which aids in weight loss by increasing muscle and burning fat. Apple peels kill prostate and breast cancer cells having ability to turn back on the cancer-suppressing protein, known as maspin. Apple peel possesses a high content of phenolic compounds which imparts anti-proliferative activity [8] and antioxidant activity [9, 10]. Antifungal and antibiotic principles are found in the peel and pulp of fully ripe fruits of Musa sapientum (banana), Family: Musaceae. Peel and pulp of green fruits of banana are active against fungal disease in tomato plants [11]. These peels have been reported to be a good source of carotenoids. It can be used in pain, swelling, itching, bruising, wrinkles and sunburn. High density sodium and lithium-ion battery anions are produced from banana peels [12]. Banana peel extract mediated synthesis of gold nanoparticles possess efficient antimicrobial activity [13]. About $50 \%$ of the total fruit weight of Puncia granatum (Pomegranate), Family: Lythraceae, corresponds to its peel. It remains an important source of bioactive compounds such as phenolics, flavonoids, ellagitannins, and proanthocyanidin compounds, minerals, mainly potassium, nitrogen, calcium, phosphorus, magnesium, sodium and complex polysaccharides. Extracts of all parts of pomegranate fruit exhibit therapeutic properties and target a range of diseases including cancer, cardiovascular disorders, diabetes, male infertility, Alzheimer's disease, aging, and AIDS. Pomegranate peels possess antioxidant, antiinflammatory, anti-allergic and antimicrobial activities [14, 15].

-Kidney stones are small, hard deposits of mineral and acid salts developed from crystals that separate from the urine within the urinary tract. Major diseases associated with kidney stones are hypercalcemia, hyperthyroidism, hyperparathyroidism, sarcoidosis, Sjogrens syndrome, Crohn's disease and other bowel diseases, especially those accompanied by malabsorption, acquired renal tubular acidosis, gout, osteoporosis/osteopenia, anorexia/bulimia, chronic urinary tract infections and neurogenic disorders that cause urine retention in kidney or bladder[16]. In many cases, the stones are very small and can pass out of the body without any problem. However, if a stone (even a small one) blocks the flow of urine, excruciating pain may result, and prompt medical treatment may be needed. Recurrent stone formation is a common part of the medical care of patients with stone disease. Calcium-containing stones, especially calcium oxalate monohydrate, calcium oxalate dihydrate and basic calcium phosphate are the most commonly occurring ones to the extent of $75-90 \%$ followed by magnesium ammonium phosphate (Struvite) to an extent of $10-15 \%$, uric acid $3-10 \%$ and cysteine $0.5-1 \%$ [17]. Medicinal plants are established as renewable sources with antiurolithiatic effects [18-20]. The selected fruit peels possess reported antioxidant activity and antioxidant dietary phytophenols are found to be effective for the prevention of urolithiasis, hence this research work was taken up to give a scientific evidence for the proposed therapeutic benefit. 


\section{MATERIALS AND METHODS}

Selected fruits were purchased from the nearby fruit market in Vijayawada, Andhra Pradesh, India. After authentication in the Department of Botany, Siddhartha arts and science college, Vijayawada, the peels (fig. 1-3) were separated, washed and subjected to drying under shade. Samples were preserved in our college museum with voucher specimen numbers MP/2016/305101A; PG/2016/305-101B; MS/2016/305-101 C. Dried peels were coarsely powdered using a household grinder and stored in airtight containers until use.

\section{Chemicals}

Calcium chloride dihydrate (Fisher Scientific), Sodium oxalate (Finar chemicals), Potassium permanganate (Loba chemicals), Oxalic acid (SD Fine Chem. Ltd), Sulphuric acid (Hi-pure Chemicals), Methanol (Loba chemicals), Hydrochloric acid (Hi-pure Chemicals), Sodium hydroxide (SD Fine Chem. Ltd), TRIS buffer (Fischer scientific), Acetone (SD Fine Chem. Ltd), Tamsulosin Hydrochloride (Dr. Reddy's)

\section{Extraction}

$100 \mathrm{~g}$ coarsely powdered peels of apple, pomegranate and banana were subjected to maceration in a stoppered conical flask with methanol at room temperature for a period of 2-3 d with frequent agitation until the soluble matter was dissolved. The resultant mixture was vacuum filtered, and the marc was re-extracted for another two days with methanol. The filtrates were combined and concentrated to obtain a crude methanol extract of the fruit peels. The air-dried marc was subjected to soxhlet extraction, using water as a solvent for 48h. All the extracts were packed into containers, labelled and stored in a desiccator until use [21]. The yield of methanol and aqueous extracts were calculated. These extracts were coded as follows:

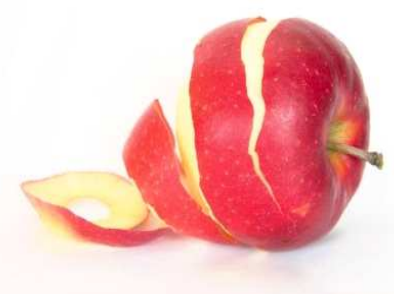

Fig. 1: Peel of Malus pumila (Apple)

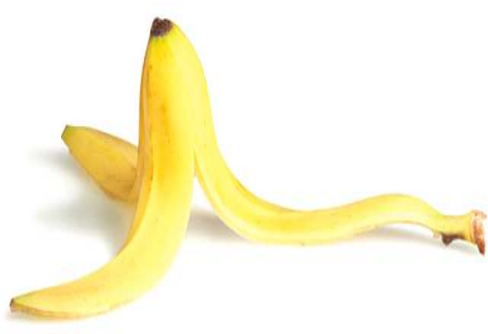

Fig. 3: Peel of Musa sapientum (Banana)

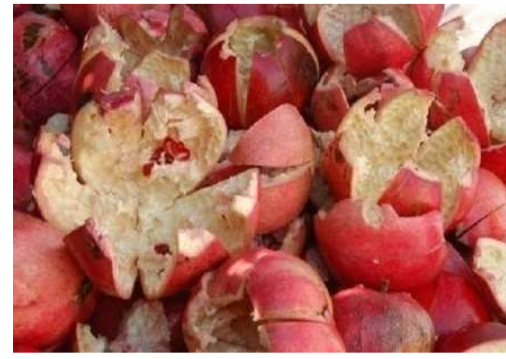

Fig. 2: Peel of Puncia granatum (Pomegranate)

Table 1: Name of extracts and their codes

\begin{tabular}{lll}
\hline S. No. & Name of the extract & Code \\
\hline 1. & apple methanol extract & AME \\
2 & apple aqueous extract & AAE \\
3 & banana methanol extract & BME \\
4 & banana aqueous extract & BAE \\
5 & pomegranate methanol extract & PME \\
6 & pomegranate aqueous extract & PAE \\
\hline
\end{tabular}

\section{Preliminary constituents screening}

The extracts were subjected to systematic phytochemical screening following standard protocol [22].

\section{Preparation of simulated renal stones by homogeneous} precipitation method

Equimolar solutions of calcium chloride dihydrate dissolved in distilled water and sodium oxalate dissolved in $10 \mathrm{ml}$ of $2 \mathrm{~N} \mathrm{H}_{2} \mathrm{SO}_{4}$ were prepared. Sufficient quantity was allowed to react in a beaker for 10$12 \mathrm{~h}$ at room temperature until white coloured crystals were formed. The resulting crystals of calcium oxalate were freed from traces of sulphuric acid by treating with ammonia solution. Finally, it was washed with distill-water and dried at $60^{\circ} \mathrm{C}$ for $4 \mathrm{~h}$. These crystals are considered to be simulated renal stones as they are practically similar to the renal stones found in patients suffering from urolithiasis [23].

\section{Separation of the semi-permeable membrane from farm eggs}

A semi-permeable membrane which lies in between the outer calcified shell and the inner contents of the farm eggs was required to evaluate the anti urolithiatic activity of the herbal extracts. A small hole was made, and the inner contents of the eggs were squeezed, the shells were washed with water and placed in $\mathrm{HCl}$ for 4-5 h. The resulting semipermeable membranes were washed thoroughly with distilled water, and placed in ammonia solution for a while and once again rinsed with distilled water. Finally, they were stored in a refrigerator at a $\mathrm{pH}$ 7-7.4 [24].

\section{Evaluation of anti-urolithiatic activity}

In vitro antiurolithiatic activity was analysed by homogeneous precipitation method of calcium oxalate stone formation and studying the ability of plant extracts to dissolve a known quantity of these simulated renal stones (calcium oxalate) placed in semipermeable membranes. A total of 8 semipermeable membranes were prepared from farm eggs. Exactly $10 \mathrm{mg}$ of calcium oxalate and $100 \mathrm{mg}$ of various fruit peel extracts/standard were weighed and packed in these semi-permeable membranes separately and were carefully sutured. The membranes were allowed to suspend in a conical flask containing $100 \mathrm{ml}$ of $0.1 \mathrm{M}$ TRIS buffer. All the conical flasks were incubated at $37^{\circ} \mathrm{C}$ for $2 \mathrm{~h}$ and later maintained at room temperature undisturbed for 7-8 $\mathrm{h}$. The unexpended calcium oxalate in the semi-permeable membranes was estimated by Kramer and Tisdal method [25] with slight modification. The contents were treated with $2 \mathrm{ml}$ of $1 \mathrm{~N}$ sulphuric acid and titrated with standard $\mathrm{KMnO}_{4}(0.9494 \mathrm{~N})$ till a permanent light pink colour was obtained $[26,27]$. The trial was repeated three times $(n=3)$, the average was calculated, and the percentage of calcium oxalate dissolved was computed. The amount of undissolved calcium was calculated from the formula:

$$
\mathrm{Z}(\mathrm{mg} \text { of Calcium retained })=\mathrm{B}(\mathrm{ml} \text { of } 0.09494 \mathrm{~N} \mathrm{KMnO4}) * 0.1898
$$

The results are displayed in table 5 and fig 4 . The experimental Protocol followed is as follows:

\section{RESULTS AND DISCUSSION}

\section{Percentage Yield}

The results of $\%$ yield are given in table 3 . Among the various fruit peel extracts, the pomegranate was found to yield the highest amount of methanol extract i.e. $5 \% \mathrm{w} / \mathrm{w}$ followed by its aqueous extract $4 \% \mathrm{w} / \mathrm{w}$. Apple peels yielded only $3 \%$ of methanol and aqueous extracts. The tested extracts are concluded to be rich in 
polar phytoconstituents. Polar phytoconstituents possess reputed therapeutic activities as reported in several research articles [28].
$\%$ Yield $=\frac{\text { Weight of extract } * 100}{\text { Weight of the dried plant material }}$

Table 2: Experimental protocol

\begin{tabular}{lll}
\hline Name of the extracts & Quantity of extract (mg) & Quantity of calcium oxalate (mg) \\
\hline AME & 100 & 10 \\
AAE & 100 & 10 \\
BME & 100 & 10 \\
BAE & 100 & 10 \\
PME & 100 & 10 \\
PAE & 100 & 10 \\
\hline
\end{tabular}

Table 3: Percentage yield

\begin{tabular}{llll}
\hline Name of extract & Weight of peels $(\mathbf{g})$ & Weight of extract $(\mathbf{g})$ & \% Yield (w/w) \\
\hline AME & 100 & 3 & 3 \\
AAE & 100 & 3 & 4.5 \\
BME & 100 & 4.5 & 3.5 \\
BAE & 100 & 3.5 & 5 \\
PME & 100 & 5 & 4 \\
PAE & 100 & 4 & 4 \\
\hline
\end{tabular}

\section{Preliminary phytochemical screening}

Preliminary phytochemical screening revealed that methanol and aqueous extracts of Malus pumila, Musa sapientum and Punica granatum possess important phytoconstituents like alkaloids, carbohydrates, glycosides, flavonoids and tannins. They belong to different categories of active constituents obtained from natural sources reported to possess therapeutic benefits [29]. The results of preliminary screening are expressed in table 4.

Table 4: Preliminary phytochemical screening

\begin{tabular}{|c|c|c|c|c|c|c|c|}
\hline S. No. & Chemical constituents & AME & AAE & BME & BAE & PME & PAE \\
\hline 1 & Alkaloids & + & - & + & - & + & + \\
\hline 2 & Carbohydrates & + & + & + & + & + & + \\
\hline 3 & Fats and Fixed Oils & - & - & - & - & - & - \\
\hline 4 & Glycosides & + & - & - & + & + & - \\
\hline 5 & Specific Glycosides & - & - & - & - & - & + \\
\hline 6 & Tannins & + & + & + & - & + & + \\
\hline 7 & Steroids and Triterpenoids & - & - & - & - & - & - \\
\hline 8 & Flavonoids & + & - & - & - & + & - \\
\hline
\end{tabular}

+indicates positive-indicates negative

\section{Anti urolithiatis activity}

Various extracts of selected fruit peels were evaluated for their ability to dissolve simulated renal stones by in-vitro technique. The amount of calcium oxalate dissolved by crude methanol extract of Musa sapientum was $9.15 \mathrm{mg}$ and percent dissolved was $91.5 \%$ in comparison to Malus pumila methanol extract with a dissolution of $8.96 \mathrm{mg}(89.6 \%)$, followed by Punica granatum methanol extracts with a dissolution of $8.0 \mathrm{mg}(80.0 \%)$. The anti urolithiatic activity of methanol extract of Musa sapientum was better than standard drug, Tamsulosin hydrochloride $(400 \mathrm{mg})$ with a percentage dissolved of about $90.05 \%$. Remaining extracts possessed activity that was comparable to tamsulosin. Musa sapientum aqueous extract exhibited the least activity with a percent dissolved of about $55 \%$.

Tamsulosinis an alpha-blocker and works by relaxing muscles in the bladder and prostate. Relaxation of these muscles relieves symptoms of Benign prostatic hyperplasia (BPH) such as difficulty in beginning the flow of urine, weak stream, and the need to urinate frequently or urgently (including during the middle of the night). When compared to allopathic medicines which target only one aspect of urolithiatic pathophysiology, medicinal plants have shown to be effective at different stages of stone pathophysiology. The expected mechanism for the phytoconstituents present in the tested extracts in the management of urolithiasis includes diuretic, antispasmodic, and antioxidant activity, as well as an inhibitory effect on crystallization, nucleation, and aggregation of crystals. Methanol extracts of Malus pumila, Musa sapientum, and Punica granatum possess significant anti-urolithiatic activity in comparison to their aqueous extracts. This has provided primary evidence for the use of Malus pumila, Musa sapientum and Punica granatum in the treatment of kidney stones. Moreover, these extracts were found to possess alkaloids, carbohydrates, tannins, flavonoids, and glycosides. Herbal plants with the phytochemicals like alkaloids, glycosides, tannins, carbohydrates, terpenoids, fats and fixed oils etc. are reported to possess anti urolithiatic activity [30-32]. As the selected peels are rich in some of these constituents, the anti urolithiatic activity may be attributed to these constituents. The results are depicted in fig. 4 . Hierarchy of antiurolithiatic activity of the samples tested is as follows:

BME $>$ Standard $>$ AME $>$ PME $>$ AAE $>$ PAE $>$ BAE .

Anti Urolithiatic Activity

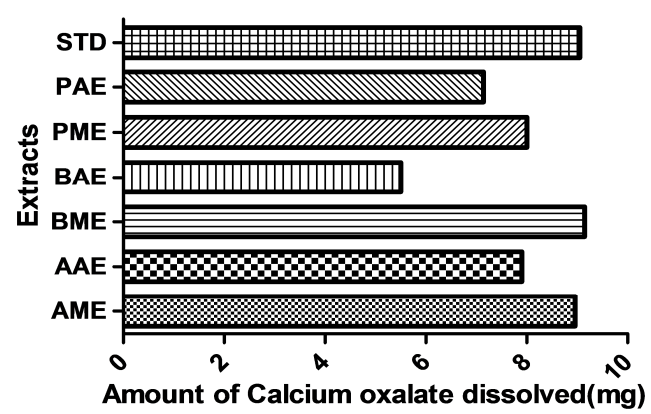

Fig. 4: Amount of calcium oxalate dissolved 


\section{CONCLUSION}

Herbs and herbal drugs have efficient pharmacological actions and potent effects on human body. Overuse of synthetic drugs, which results in higher incidence of adverse drug reactions, has motivated humans to return to nature for safe remedies. Urolithiasis is one of the serious problems associated with kidney health which may be fatal if left untreated. These experimental results proved prominent anti urolithiatic activity of the fruit peel extracts when compared to the standard. Therefore we conclude that all the selected fruit peels can be used in the treatment of renal stones. Further, in vivo studies are needed to give a strong scientific basis for these in vitro findings.

\section{ACKNOWLEDGMENT}

The authors wish to thank The Principal and the management of $\mathrm{K}$. V. S. R. Siddhartha College of pharmaceutical sciences, Vijayawada, for providing the facilities for successful completion of the work.

\section{AUTHORS CONTRIBUTIONS}

All authors have equal contribution

\section{CONFLICTS OF INTERESTS}

\section{None}

\section{REFERENCES}

1. Rajbir Kaur, Saroj Arora. Alkaloids-important therapeutic secondary metabolites of plant origin. J Crit Rev 2015;2:1-8.

2. Martins E. The growing use of herbal medicines: issues relating to adverse reactions and challenges in monitoring safety. Front Pharmacol 2013;4:177.

3. Ibrahim UK, Kamarruddin N, Suzihaque MUH, Abd Hashib Smarr. Local fruit wastes as a potential source of natural antioxidant: an overview. IOP Conference Series: Materials Science Engineering 2017;206:1-9.

4. James M Lattimer, Mark D Haub. Effects of dietary fibre and its components on metabolic health. Nutrients 2010;2:1266-89.

5. Shilpi C. Therapeutic fruit peels: their role in preventing lifestyle disorders. Recent Res Sci Technol 2014;6:283-6.

6. Jedrychowski W, Maugeri U. An apple a day may hold colorectal cancer at bay: recent evidence from a case-control study. Rev Environ Health 2009;24:59-74.

7. Ramakrishna M, Suresh V. Apple peels-a versatile biomass for water purification. ACS Appl Mater Interfaces 2013;5:4443-9.

8. Jia-Ren Liu. Proliferative activity of the fresh apple peels. J Agric Food Chem 2008;57:297-304.

9. Kelly Wolfe, Xiangzhong Wu, Rui Hai Liu. Anti-oxidant activity of apple peels. J Agric Food Chem 2003;51:609-14.

10. Gonzalez Montelonga M, Gloria L, Monica G. Antioxidant activity in banana peel extracts: testing extraction conditions and related bioactive compounds. Food Chem 2010;11:1030-9.

11. Sampath Kumar KP, Dedjit Bhowmik, Duraivel S, Umadevi M. Traditional and medicinal uses of banana. J Pharmacogn Phytochem 2012;1:51-63.

12. Lotfabad EM, Ding J, Cui K, Kohandehghan A, Kalisvaart WP, Hazeiton M, et al., High-density sodium and lithium-ion battery anodes from banana peels. ACS Nanotechnol 2014;8:7115-29.
13. Bankar A, Joshi B, Kumar AR, Zinjarde S. Mediated synthesis of gold nanoparticles. Colloids Surf B 2010; 80:45-50.

14. Huang DO, Prior BR. The chemistry behind antioxidant capacity assays. J Agric Food Chem 2005;53:1841-56.

15. Li Y, Guo C, Yang J, Wei J. Evaluation of antioxidant properties of pomegranate peel extract in comparison with pomegranate pulp extract. Food Chem 2006;96:254-60.

16. Tushar Shelke, Sandesh Wayal, Shiv Gunjegaokar, Sachin Gaikwad, Amol Shrisath, Sunil Hadke. An overview on Indian medicinal plants with antiurolithiatic activity. J Pharm Res Clin Practice 2014;4:33-40.

17. Elaine MW, Fredric LC. Clinical practice calcium kidney stones. N Engl J Med 2010;363:954-63.

18. Biljiana Bauer P, Bauer P. Historical review of medicinal plant's usage. Pharmacogn Rev 2012;6:1-5.

19. Anubhav N, Rajeev KS. Herbal resources with antiurolithiatic effects: a review. Indo Global J Pharm Sci 2013;3:6-14.

20. Sathish R, Natarajan K, Mukesh Madhavrao N. Effect of Hygrophila Spinosa T. anders on ethylene glycol induced urolithiasis in rats. Asian J Pharm Clin Res 2010;3:61-3.

21. Sunil Kumar KN, Suchitra Narayan Prabhu, Ravishankar B, Sahana, Yashovarma B. Chemical analysis and in vitro evaluation of antiurolithiatic activity of Aerva lanata (Linn.) Juss. Ex Schult. Roots. J Pharmacogn Phytochem 2015;3:2.

22. Kokate CK. Practical Pharmacognosy. $4^{\text {th }}$ ed. Delhi (India): Vallabh Prakashan; 2003.

23. Babior BM. Phagocytes and oxidative stress. Am J Med 2000;109:33-44.

24. Rohan Sharada and P, Anup Subhash H. In vitro antiurolithiatic activity of Kalanchoe pinnata extract. Int J Pharmacogn Phytochem Res 2015;7:276.

25. Kramer B, Tisdall FF. A note on the kramer-tisdall method for the determination of calcium in small amounts of serum. J Biol Chem 1921;xlvii:475.

26. Suresh Babu S, Chitra CK, Venkat Rao N, Naveen Kumar S. Evaluation of antiurolithiatic activity of alcoholic extract of roots of Cissampelos pareira in albino rats. J Clin Diagn Res 2014;8:1.

27. Niharika M, Harshitha V, Ashwini P, Srivinya B, Himabindhu J, Ramanjaneyulu K. Evaluation of in vitro antiurolithiatic activity of Chloris barbata. Int J Curr Pharm Res 2018;10:65-7.

28. Ruan ZP, Zhang LL, Lin YM. Evaluation of the antioxidant activity of Syzygium cumini leaves. Molecules 2008;13:2545-56.

29. Naczk M, Shahidi F. Phenolics in cereals, fruits and vegetables: occurrence, extraction, and analysis. J Pharm Biomed Anal 2006;41:1523-42.

30. Ashok P, Basavaraj C, Vishwanathaswamy AHM. Antiurolithiatic and antioxidant activity of Mimusops elengi on ethylene glycol-induced urolithiasis in rats. Indian J Pharmacol 2010;42:380-3.

31. Yogendra MB, Neeraj Kumar. Phytochemical and pharmacological evaluation of Hedychium coronarium for antiurolithiatic activity. World J Pharm Sci 2014;2:112-22.

32. Basavaraj Poojar, Huban Thomas, Shalini Adiga, Huban Thomas. Evaluation of antiurolithiatic property of ethanolic extract of fennel seeds in male wistar albino rats. Asian J Pharm Clin Res 2017;10:313-6. 